\title{
EFEITO DAS TEMPERATURAS DE BOBINAMENTO E ENCHARQUE NAS PROPRIEDADES MECÂNICAS DE UM AÇO LAMINADO A FRIO MICROLIGADO AO NIÓBIO*
}

\author{
Saulo Morais de Andrade ${ }^{1}$ \\ Fagner de Carvalho Oliveira ${ }^{2}$ \\ Maria Amélia Martins ${ }^{3}$
}

\begin{abstract}
Resumo
Aços de alta resistência mecânica têm sido aplicados largamente no setor automotivo para redução do peso veicular e aumento da segurança. $O$ aço de alta resistência e baixa liga ( $A R B L)$ é um dos exemplos de materiais utilizados em peças estruturais e de reforço dos automóveis. Nesse trabalho foi avaliado o efeito das temperaturas de bobinamento e encharque nas propriedades mecânicas do aço ARBL laminado a frio microligado ao nióbio, com limite de escoamento mínimo de $410 \mathrm{MPa}$, produzido em escala industrial. De uma forma geral, foram observados queda nos limites de escoamento e resistência, e aumento do alongamento total do aço com a elevação das temperaturas avaliadas. Foi observado que a temperatura de encharque apresentou uma maior influência, ocasionando uma maior queda na resistência mecânica. Como não foram verificadas alterações significativas no tamanho de grão ferrítico, as variações nos valores de propriedades mecânicas podem ser atribuídas ao coalescimento de precipitados.
\end{abstract}

Palavras-chave: Aços ARBL; Propriedades mecânicas; Temperatura de bobinamento; Temperatura de encharque.

\section{EFFECT OF COILING TEMPERATURE AND SOAKING TEMPERATURE ON MECHANICAL PROPERTIES OF A COLD-ROLLED STELL MICROALLOYED WITH NIOBIUM}

\section{Abstract}

High strength steels have been widely applied in the automotive industry to reduce vehicle weight and increase safety. The high strength low alloy steel (HSLA) is one of the examples of materials that are used in structural and reinforcement parts of the car. In this study was evaluated the effect of coiling temperature and soaking temperature on mechanical properties of cold-rolled HSLA steel, niobium microalloyed, with a minimum yield strength of $410 \mathrm{MPa}$. In general it was observed a decrease in yield strength and tensile strength and an increase in stell total elongation with rising temperatures evalueted. It was observed that the soaking temperature had a greater influence, causing a major decrease in mechanical resistence. As no significant changes were observed in the ferritic grain size, variations in mechanical properties values can be attributed to the coarsening of precipitates.

Keywords: HSLA steels; Mechanical properties; Coiling temperature; Soaking temperature.

1 Engenheiro Metalurgista, Engenheiro de Produção, Gerência Técnica de Laminação a Frio, Usiminas, Ipatinga, Minas Gerais, Brasil.

2 Engenheiro Metalurgista, Engenheiro de Produto Pleno, Gerência de Controle Integrado do Produto, Usiminas, Ipatinga, Minas Gerais, Brasil.

3 Engenheira Metalurgista, Mestranda em Engenharia de Materiais, Universidade Federal de Ouro Preto, Ouro Preto, Minas Gerais, Brasil. 


\section{INTRODUÇÃO}

Os aços planos são aplicados em vários setores da economia, sendo sua principal utilização na indústria automotiva. Para melhorar a qualidade e reduzir o custo de fabricação de seus produtos a indústria automotiva vem exigindo características restritas em relação às propriedades mecânicas dos aços ali aplicados.

Dentre os requisitos solicitados, o aumento de resistência mecânica é um dos fatores primordiais. Os aços de alta resistência promovem uma oportunidade única para redução do peso, via redução da espessura da chapa, sem trazer prejuízos à segurança veicular. Essa redução do peso do veículo proporciona um menor consumo de combustível e, consequentemente, uma menor emissão de gases poluentes [1].

Em meio aos vários tipos de aços de alta resistência, estão à família dos aços de Alta Resistência e Baixa Liga (ARBL). Esses aços apresentam limite de escoamento entre $250 \mathrm{MPa}$ e $650 \mathrm{MPa}$, são soldáveis e de boa resistência mecânica, tenacidade e ductilidade e caracterizam-se por adições de pequeno percentual de nióbio, vanádio e/ou titânio [2]. Conforme Pradhan elevados níveis de resistência podem ser alcançados através do refino de grão e do endurecimento por precipitação, ligados aos carbonitretos formados por esses elementos [3]. Um aumento no endurecimento pode ser alcançado pela adição dos elementos fósforo, manganês e/ou silício, que provocam um endurecimento por solução sólida.

Além da composição química, vários parâmetros de processo exercem influência sobre as propriedades mecânicas do produto final. Na laminação a quente, por exemplo, destacam-se as temperaturas de reaquecimento de placas, de bobinamento e de acabamento. Já na laminação a frio, a taxa de deformação a frio, a temperatura de encharque do recozimento após laminação a frio e o encruamento (skin pass) são alguns dos parâmetros que devem ser considerados para controle dos valores de propriedades mecânicas.

A temperatura de bobinamento influencia o tamanho e a morfologia dos grãos de ferrita e perlita, e também afeta a morfologia dos precipitados [4]. Além disso, 0 estudo de Melo e Blas indica que o endurecimento por precipitação em aços ARBL atinge o seu máximo em temperaturas de bobinamento próximas a $600^{\circ} \mathrm{C}$. Para temperaturas mais baixas a resistência mecânica cai devido à redução da fração de precipitados. Já em temperaturas mais elevadas, a redução dos valores de propriedade mecânica pode ser justificada pelo coalescimento dos precipitados os tornando mais grosseiros [5].

A influência das etapas de encharque, resfriamento primário e superenvelhecimento do processo de recozimento contínuo de um aço ARBL, microligado ao nióbio, foram avaliadas por Barbosa et alli [6]. Nesse estudo, os autores verificaram que a etapa de encharque exerceu maior influência sobre as propriedades mecânicas. $O$ encharque consiste na manutenção do material em uma determinada temperatura por certo tempo para que ocorra a recristalização seguida do crescimento de grão [2]. Pequenas variações na temperatura de encharque podem provocar significativas variações nas propriedades mecânicas [6].

Este trabalho teve como objetivo avaliar o efeito da temperatura de bobinamento da laminação a quente e de encharque do recozimento contínuo, nas propriedades mecânicas de um aço microligado ao nióbio laminado a frio. 


\section{MATERIAIS E MÉTODOS}

O aço utilizado no trabalho foi produzido em escala industrial visando atender o limite de escoamento mínimo de $410 \mathrm{MPa}$ no produto final laminado a frio e recozido. A tabela 1 mostra a faixa de composição química utilizada para produção do aço ARBL.

Tabela 1. Faixa de composição química do aço ARBL avaliado (\%peso)

\begin{tabular}{c|c|c|c|c|c}
\hline $\mathbf{C}$ & $\mathbf{S i}$ & $\mathbf{M n}$ & $\mathbf{P}$ & $\mathbf{A l}$ & $\mathbf{N b}$ \\
\hline$<0,15$ & $<0,60$ & $<1,80$ & $<0,03$ & 0,01 a 0,08 & 0,02 a 0,06 \\
\hline
\end{tabular}

$\mathrm{Na}$ etapa de laminação a quente as placas provenientes da aciaria com a composição química desejada foram introduzidas em um forno de reaquecimento. Após o reaquecimento, as placas foram processadas em laminadores desbastadores e em um laminador acabador de seis cadeiras, reduzindo a espessura de $250 \mathrm{~mm}$ para $3,5 \mathrm{~mm}$. Os materiais laminados a quente foram bobinados com temperaturas de $600^{\circ} \mathrm{C}$ e $630^{\circ} \mathrm{C}$. Os demais parâmetros dessa etapa de produção foram mantidos conforme o padrão de processo industrial.

As bobinas laminadas a quente foram decapadas para retirada da camada de óxidos formada durante o processo de laminação a quente, utilizando uma solução de ácido clorídrico $(\mathrm{HCl})$. Elas foram laminadas a frio em um laminador de cinco cadeiras com redução de espessura de, aproximadamente, $56 \%$, chegando a uma espessura final de $1,55 \mathrm{~mm}$.

Após a laminação a frio o material foi submetido ao processo de recozimento contínuo. Esse processo compõe-se por etapas de limpeza eletrolítica, recozimento, encruamento e acabamento.

O ciclo de recozimento contínuo empregado para o tratamento térmico do material laminado a frio esta esquematizado na figura 1. As bobinas foram processadas com temperaturas de encharque de $800^{\circ} \mathrm{C}$ e $820^{\circ} \mathrm{C}$, durante o tempo de 75 segundos.

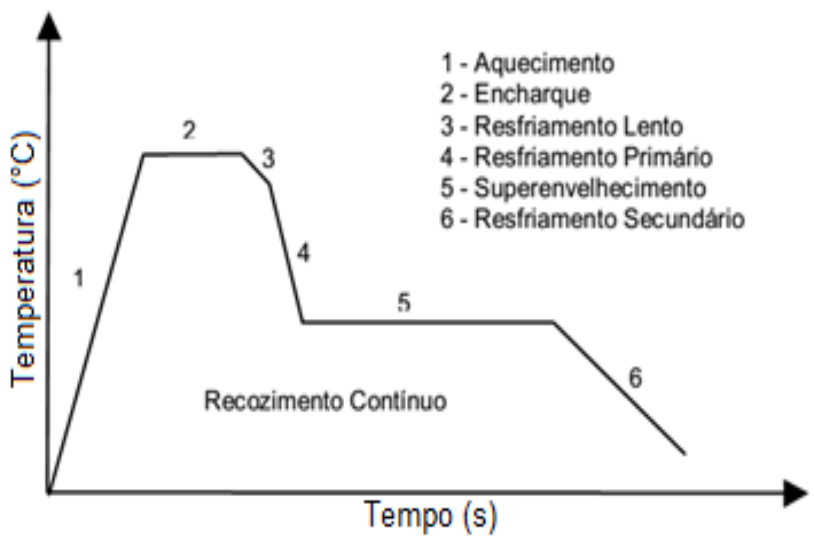

Figura 1. Ciclo esquemático de recozimento contínuo.

Ao todo foram avaliadas três condições variando a temperatura de bobinamento da laminação a quente ou de encharque do recozimento contínuo. O efeito da temperatura de bobinamento foi avaliado apenas nas bobinas processadas com temperatura de encharque igual a $800^{\circ} \mathrm{C}$, e o efeito da temperatura de encharque foi avaliado apenas nas bobinas processadas com temperatura de bobinamento igual a $600^{\circ} \mathrm{C}$. A tabela 2 mostra quais foram essas combinações. 
Tabela 2. Combinações de temperaturas testadas

\begin{tabular}{c|c|c}
\hline Condição & Temperatura de bobinamento $\left({ }^{\circ} \mathbf{C}\right)$ & Temperatura de encharque $\left({ }^{\circ} \mathbf{C}\right)$ \\
\hline 1 & 600 & 800 \\
\hline 2 & 600 & 820 \\
\hline 3 & 630 & 800 \\
\hline
\end{tabular}

A amostragem foi realizada em bobinas laminadas a frio e recozidas (BF's). Ao todo foram processadas dezoito BF's e retiradas dez amostras em cada, sendo cinco no topo e cinco na base.

Ensaios de tração e metalografia foram realizados para caracterização do material visando identificar possíveis influências das variáveis estudadas nas propriedades mecânicas.

Os ensaios de tração foram realizados conforme a norma JIS-Z-2241, na direção transversal ao sentido de laminação, para cada amostra retirada nas BF's [7]. Os corpos de prova (CP's) utilizados nos ensaios foram retirados a $1 / 4$ da largura da amostra. Os CP's foram ensaiados em uma máquina de tração INSTRON de $10 \mathrm{t}$. Nesse ensaio foi avaliado o limite de escoamento, o limite de resistência e o alongamento total.

As análises metalográficas foram realizadas com intuito de determinar o tamanho de grão ferrítico. Esse ensaio foi realizado em um microscópio óptico utilizando o método de interceptos baseado na norma ASTM-E-112 [8].

\section{RESULTADOS E DISCUSSÃO}

\subsection{Análise Metalográfica}

As análises metalográficas realizadas não evidenciaram alterações significativas no tamanho de grão ferrítico com variações das temperaturas de bobinamento da laminação a quente e encharque do recozimento contínuo. O tamanho de grão obtido em todas as condições avaliadas foi 14 , conforme classificação da norma ASTM-E-112 [8].

Nas figuras 2 a 4 são mostrados os aspectos representativos das microestruturas obtidas em cada condição de processamento avaliada. As amostras foram atacadas com Nital $3 \%$ e fotografadas com ampliação de 500 vezes.

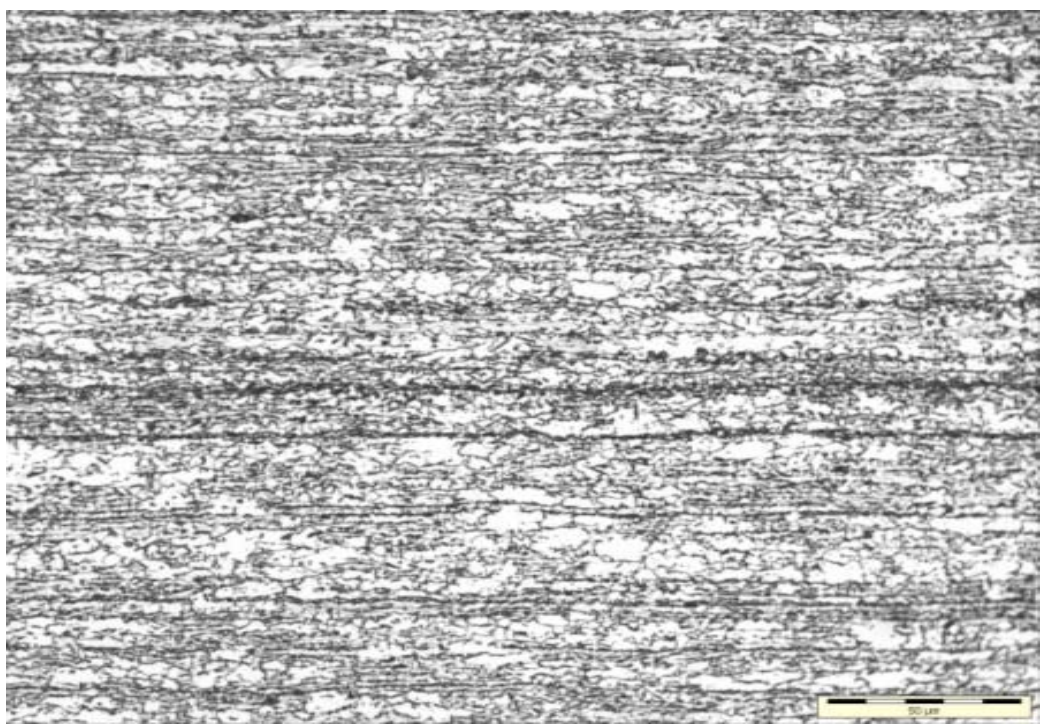

Figura 2. Aspecto representativo da microestrutura obtida com o processamento da condição 1. 


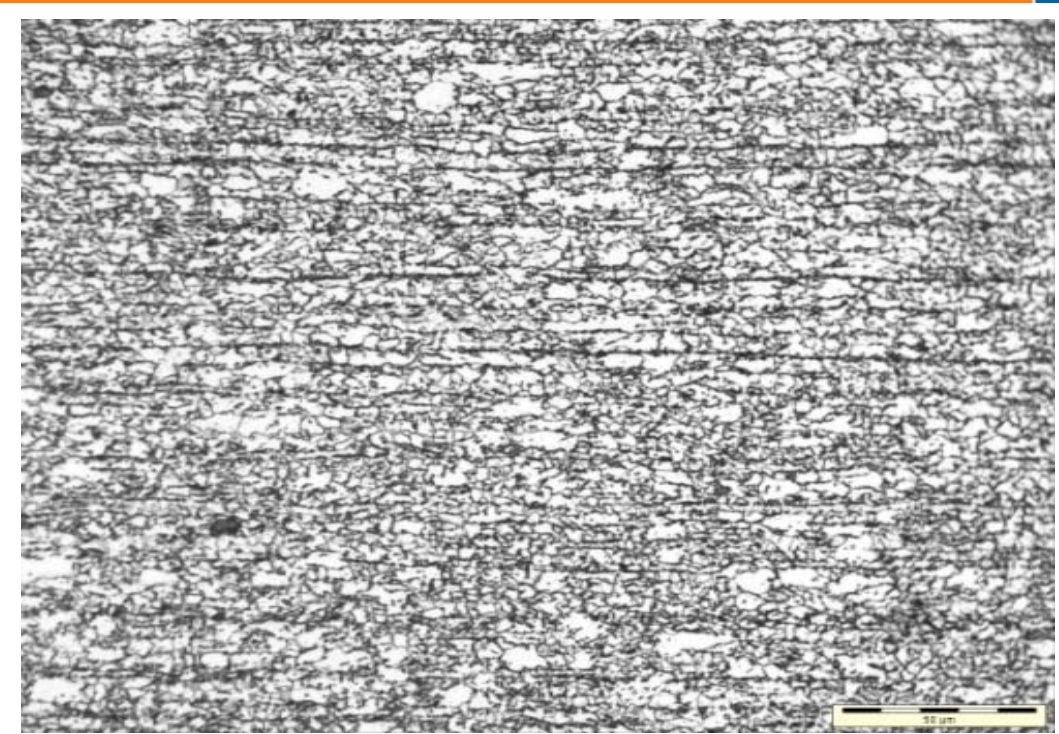

Figura 3. Aspecto representativo da microestrutura obtida com o processamento da condição 2.

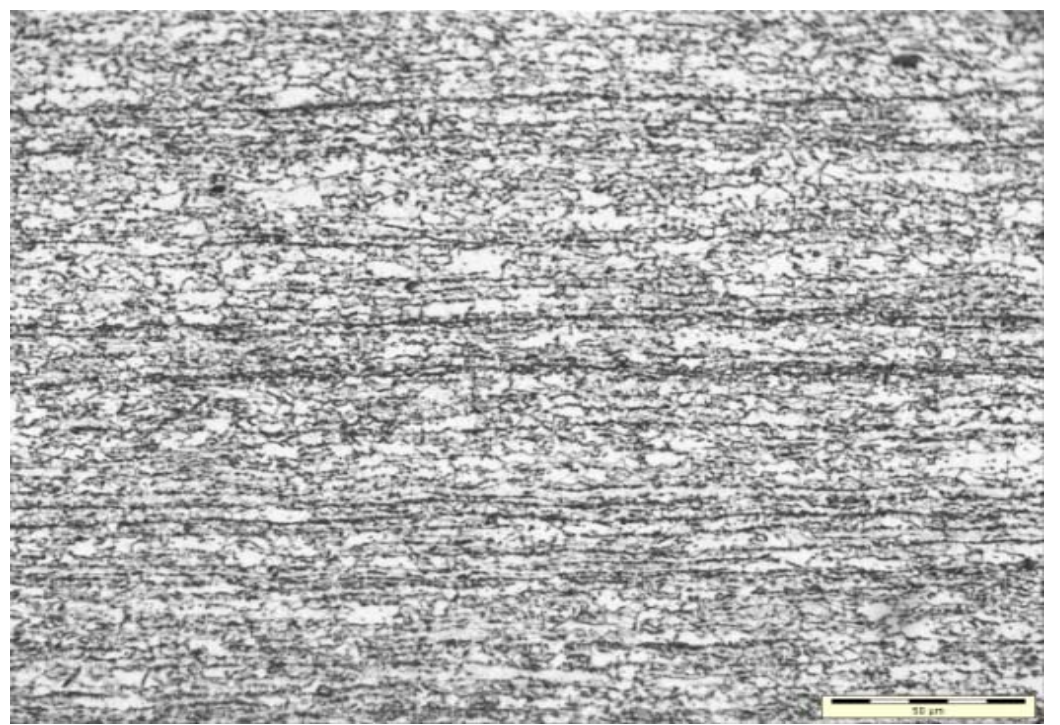

Figura 4. Aspecto representativo da microestrutura obtida com o processamento da condição 3.

\subsection{Propriedades Mecânicas Obtidas no Ensaio de Tração}

Os valores médios e o desvio padrão do limite de escoamento, limite de resistência e alongamento total, obtidos para cada condição de processamento são mostrados na tabela 3.

Tabela 3. Valores de propriedade mecânica e desvio padrão obtidas no ensaio de tração

\begin{tabular}{c|c|c|c}
\hline Condição & LE (MPa) & LR (MPa) & Along total (\%) \\
\hline 1 & $485(11)$ & $636(7)$ & $23,4(1,1)$ \\
\hline 2 & $454(12)$ & $615(10)$ & $25,5(1,1)$ \\
\hline 3 & $478(17)$ & $626(9)$ & $24,1(1,0)$ \\
\hline
\end{tabular}

\subsubsection{Efeito da temperatura de bobinamento}

O efeito da temperatura de bobinamento nos valores de propriedades mecânicas em tração foi avaliado nas bobinas processadas com temperatura de encharque igual a $800^{\circ} \mathrm{C}$. 
Nas figuras 5 a 7 são mostrados os comportamentos da média e do desvio padrão das propriedades mecânicas, com a alteração da temperatura de bobinamento. É possível verificar que houve uma redução do LE e LR e aumento do alongamento total, com a elevação da temperatura de bobinamento.

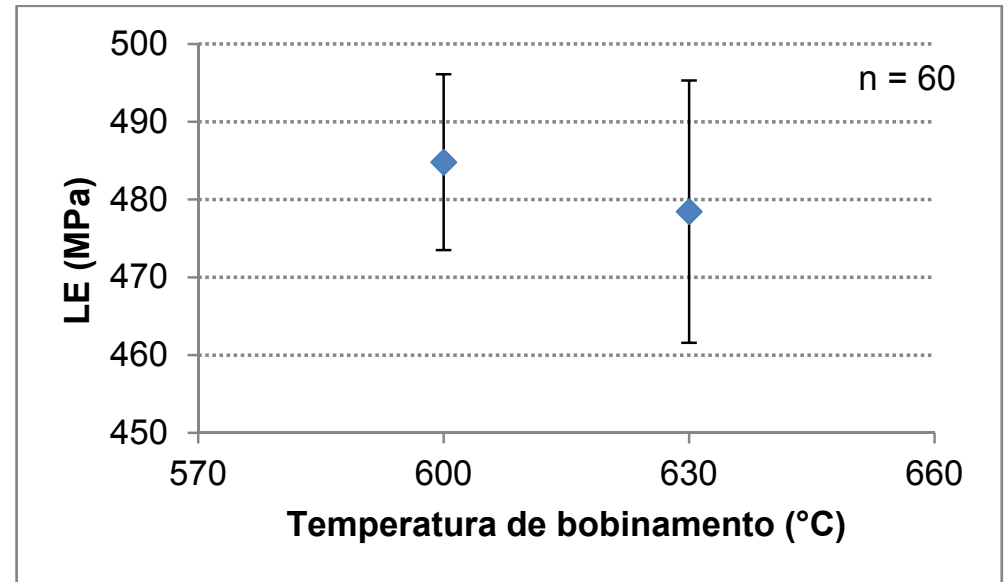

Figura 5. Comportamento do LE com variação da temperatura de bobinamento.

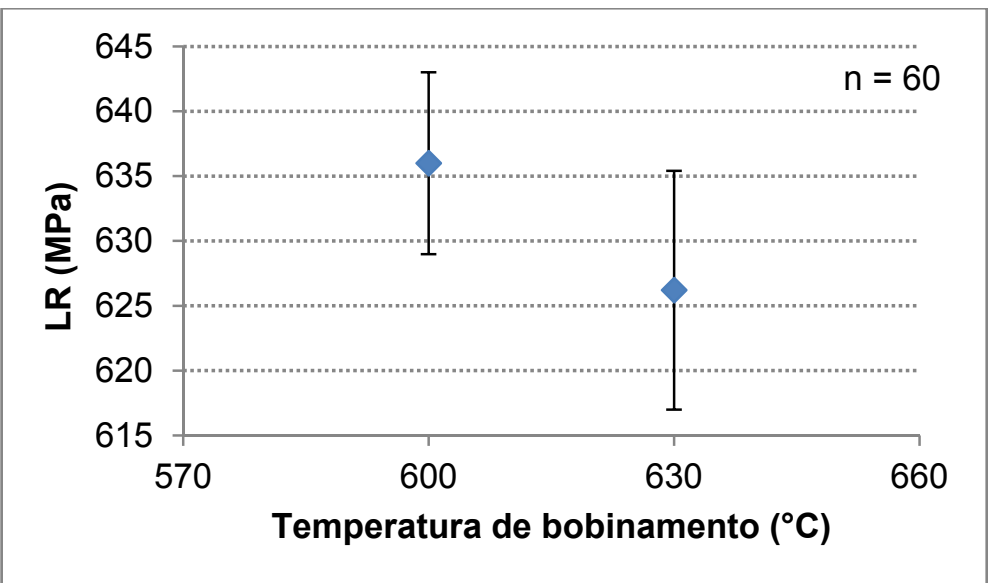

Figura 6. Comportamento do LR com variação da temperatura de bobinamento.

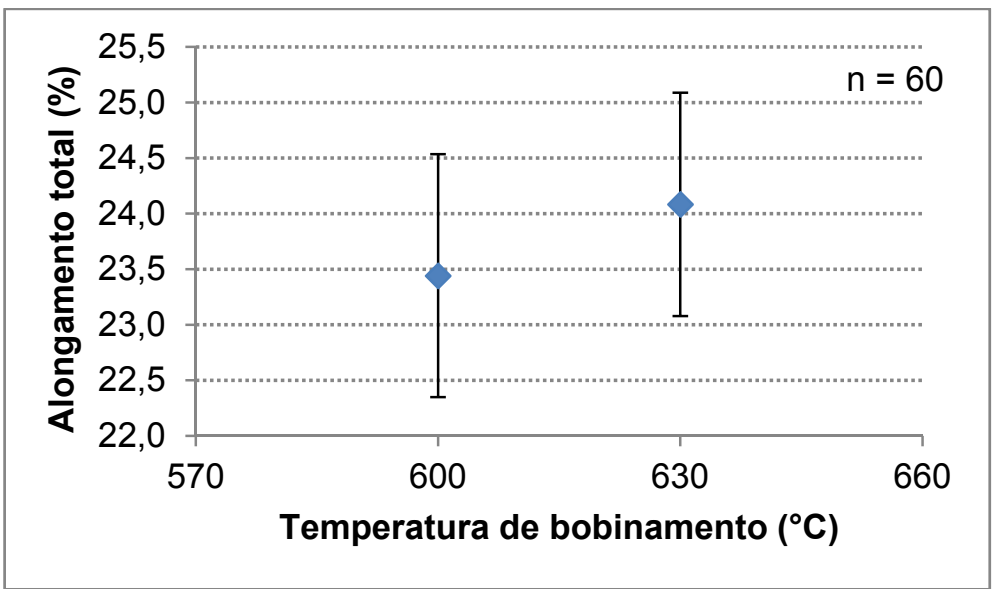

Figura 7. Comportamento do alongamento total com variação da temperatura de bobinamento.

Análises de variância de cada propriedade obtida no ensaio de tração evidenciaram, com $95 \%$ de certeza, que a temperatura de bobinamento exerceu influência nas propriedades mecânicas do aço testado. Nesse tipo de análise estatística foi 
avaliado o valor-P para cada propriedade. Esse valor representa a probabilidade de se observar diferenças entre grupos, neste caso entre o material bobinado a $600^{\circ} \mathrm{C} \mathrm{e}$ a $630^{\circ} \mathrm{C}$. Para o presente trabalho o valor-P inferior a 0,05 evidencia que há uma diferença que deve ser considerada entre os grupos, ou seja, a diferença entre as médias é significativa. $\mathrm{O}$ valor-P de cada propriedade é mostrado na tabela 4.

Tabela 4. Valor-P das propriedades comparadas com alteração da temperatura de bobinamento

\begin{tabular}{c|c}
\hline Propriedade & Valor-P \\
\hline LE & 0,016 \\
\hline LR & $4,57 \times 10^{-10}$ \\
\hline Alongamento total & 0,001 \\
\hline
\end{tabular}

\subsubsection{Efeito da temperatura de encharque}

O efeito da temperatura de encharque nas propriedades mecânicas em tração foi avaliado nas bobinas processadas com temperatura de bobinamento de $600^{\circ} \mathrm{C}$.

Nas figuras 8 a 10 são mostrados os comportamentos da média e do desvio padrão das propriedades mecânicas com a alteração da temperatura de encharque. Assim como aconteceu com o aumento da temperatura de bobinamento, o aumento da temperatura de encharque resultou numa redução do LE e LR médio e elevação do alongamento total médio.

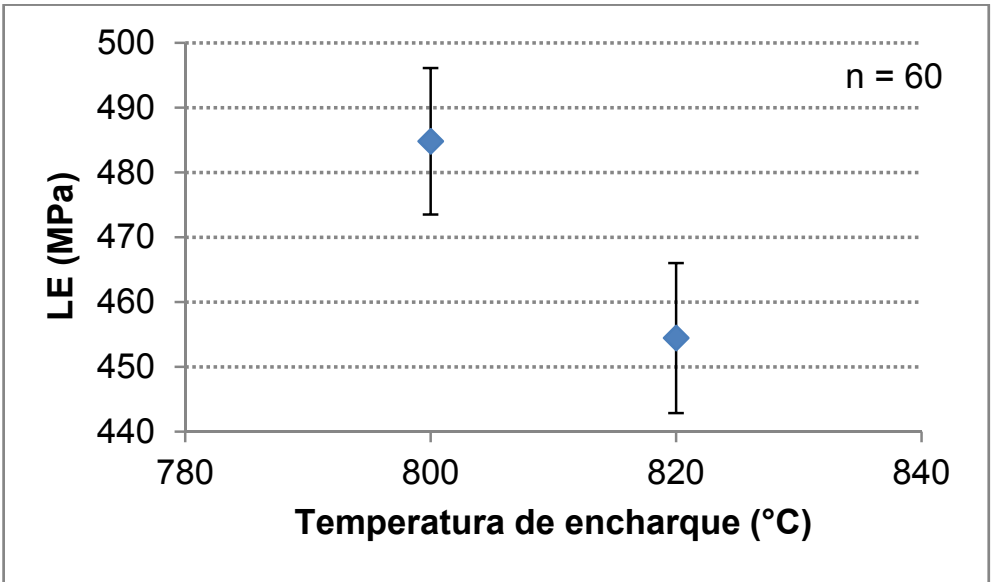

Figura 8. Comportamento do LE com variação da temperatura de encharque.

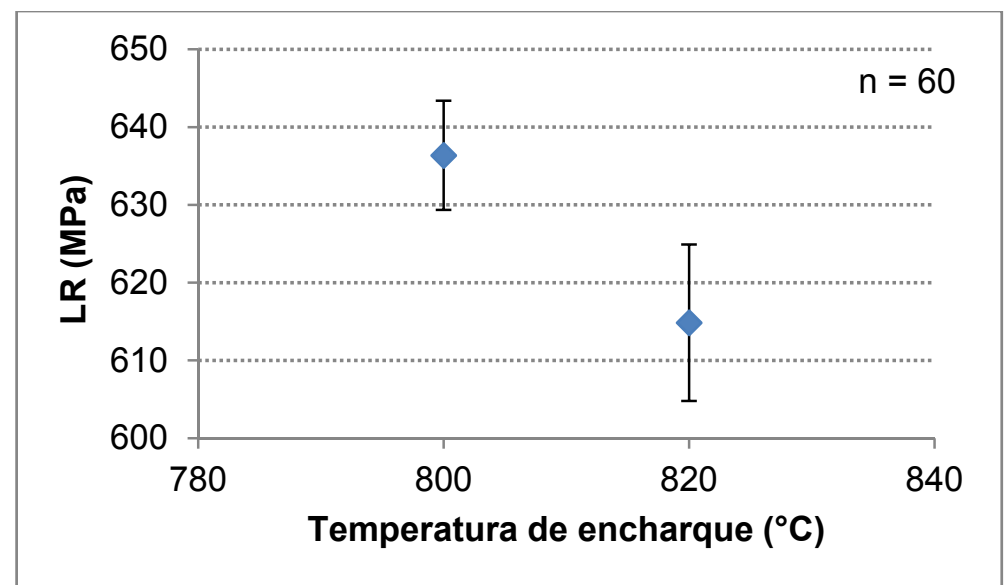

Figura 9. Comportamento do LR com variação da temperatura de encharque. 


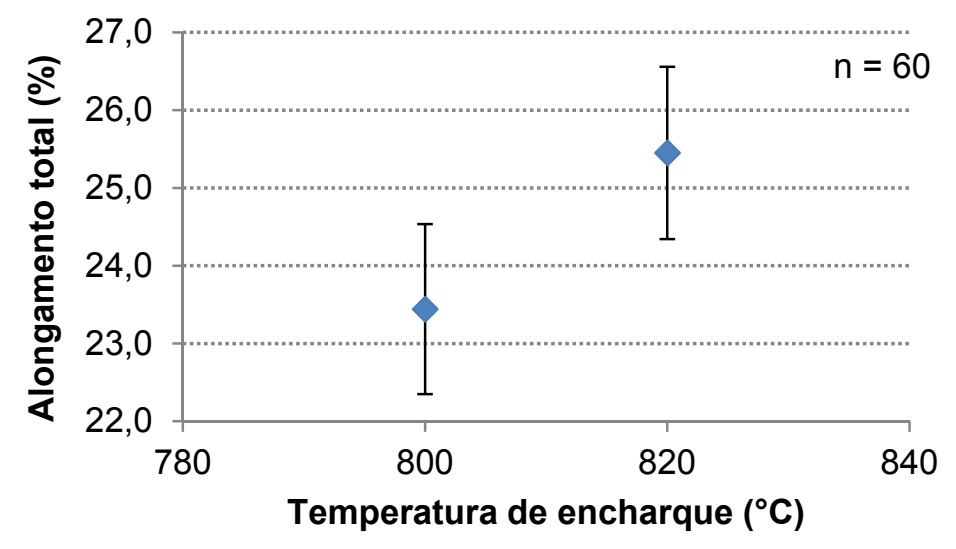

Figura 10. Comportamento do alongamento total com variação da temperatura de encharque.

Análises de variância também foram realizadas para cada propriedade obtida no ensaio de tração. Conforme o resultado obtido pode-se afirmar, com $95 \%$ de certeza, que a temperatura de encharque exerceu influência nas propriedades mecânicas do aço. O valor-P de cada propriedade é mostrado na tabela 5 .

Tabela 5. Valor-P das propriedades comparadas com alteração da temperatura de encharque

\begin{tabular}{c|c}
\hline Propriedade & Valor-P \\
\hline LE & $4,49 \times 10^{-28}$ \\
\hline LR & $6,79 \times 10^{-26}$ \\
\hline Alongamento total & $2,05 \times 10^{-17}$ \\
\hline
\end{tabular}

As variações das propriedades mecânicas do aço com as alterações da temperatura de bobinamento e de encharque podem ser atribuídas ao coalescimento de precipitados, uma vez que não foram observadas alterações significativas no tamanho de grão. Resultados semelhantes também foram verificados em trabalhos de literatura [1-6].

Vale destacar que a variação da temperatura de encharque exerceu uma maior influência nas propriedades mecânicas, conforme pode ser observado na tabela 6 . Tal fenômeno pode ser atribuído às altas temperaturas praticadas no recozimento contínuo, mais próximas às temperaturas de solubilização dos precipitados, que podem ter promovido um maior coalescimento, em comparação com o aumento da temperatura de bobinamento [6].

Tabela 6. Comparação da influência de cada parâmetro avaliado na média dos valores de propriedade mecânica

\begin{tabular}{c|c|c|c}
\hline Parâmetro & LE (MPa) & LR (MPa) & Along (\%) \\
\hline Aumento de $30^{\circ} \mathrm{C}$ na temperatura de bobinamento & -7 & -10 & 0,7 \\
\hline Aumento de $20^{\circ} \mathrm{C}$ na temperatura de encharque & -31 & -21 & 2,1 \\
\hline
\end{tabular}

\section{CONCLUSÃO}

Nenhuma das condições testadas alterou de forma significativa o tamanho de grão ferrítico, sendo obtido nas medições o tamanho de grão de 14 ASTM.

Os resultados das análises de variância permitem afirmar que o aumento da temperatura de bobinamento de $600^{\circ} \mathrm{C}$ para $630^{\circ} \mathrm{C}$ afetou as propriedades mecânicas do aço. Houve uma queda no LE e LR médio de, respectivamente, 
$7 \mathrm{MPa}$ e $10 \mathrm{MPa}$, e aumento de $0,7 \%$ no alongamento total médio. Contudo, as propriedades mecânicas do aço se mostraram mais sensíveis com a elevação da temperatura de encharque. Esse comportamento pode ser explicado pelo processamento das bobinas em temperaturas de encharque próximas a de solubilização dos precipitados. $\mathrm{O}$ aumento de $20^{\circ} \mathrm{C}$, passando de $800^{\circ} \mathrm{C}$ para $820^{\circ} \mathrm{C}$, ocasionou uma queda de $31 \mathrm{MPa}$ no LE médio e de $20 \mathrm{MPa}$ no LR médio. O alongamento total médio aumentou $2,1 \%$.

A queda da resistência do aço com aumento das temperaturas de bobinamento e encharque pode ser associada ao coalescimento de precipitados, uma vez que não foram evidenciadas variações significativas no tamanho de grão.

\section{REFERÊNCIAS}

1 PATEL, J. K.; WILSHIRE, B. The Challenge to Produce Consistent Mechanical Properties in Nb-HSLA Strip Steels. Journal of Materials Processing Technology, v. 120, p. 316-321, 2002.

2 FERNANDES, Rogério Carlos Oliveira. Efeito da Temperatura de Encharque no Recozimento Contínuo e da Deformação na Laminação de Encruamento sobre as Propriedades Mecânicas de um Aço Microligado Laminado a Frio. 2007. 93 f. Dissertação (mestrado) - Universidade Federal de Minas Gerais.

3 PRADHAN, R. High Strength/High Yield-Ratio Cold-Rolled Steels Produced by Continuos Annealing. ScandinavianJournalMetallurgy, v.13, n.5, p. 298-307, 1984.

4 MELO, Emerson Guimarães. Efeito das Temperaturas de Reaquecimento de Placas e de Bobinamento nas Propriedades Mecânicas em Tração de um Aço Microligado ao Nióbio Laminado a Frio. 2006. 59 f. Dissertação (mestrado) - Universidade Federal de Minas Gerais.

5 MELO, M. P. S.; BLAS, J. C. G. Propriedades Mecânicas e Microestruturais dos Aços Microligados ao Nb e Nb-V. $47^{\circ}$ Congresso anual da ABM, 1992, Belo Horizonte. p. 6996.

6 BARBOSA, A. H. A.; PEREIRA, J. F. B.; RIBEIRO, C. F. Influência dos Parâmetros de Recozimento Contínuo na Produção de Aços ARBL Laminados a Frio. Metalurgia e Materiais, São Paulo, v. 58, n. 521, p. 37-42, maio 2002.

7 JAPANESE INDUSTRIAL STANDARD. JIS Z 2241: Method of Tensile Test for Metallic Materials. 1998.

8 AMERICAN SOCIETY FOR TESTING AND MATERIALS. ASTM E-112: Standard Test Methods for Determining Average Grain Size. 2013. 